\title{
Chronic intake of high-dose of blueberry leaf extract does not augment the harmful effects of ethanol in rats
}

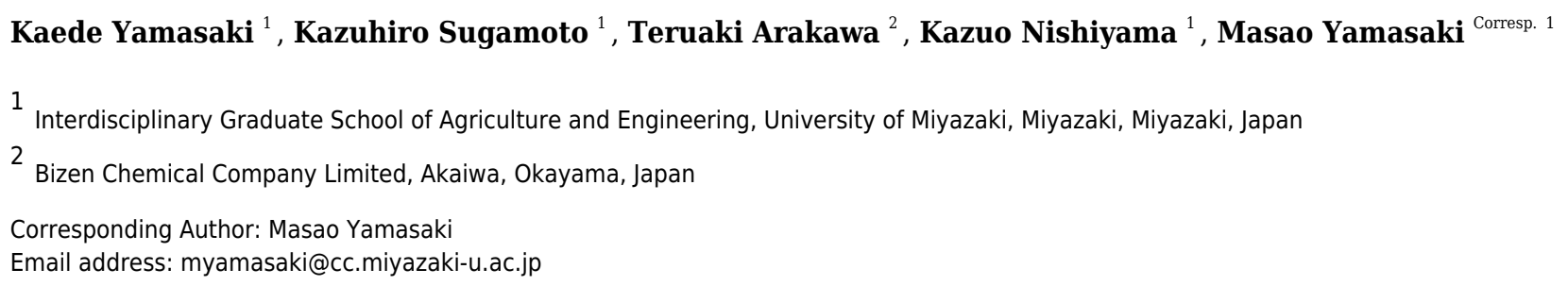

Excessive alcohol consumption is a risk factor for liver diseases. Enhancement of alcohol metabolism could be an effective strategy to prevent these adverse effects since it promotes the clearance of ethanol and acetaldehyde from the serum. Polyphenol-rich products have shown to protect against alcohol-related liver damage. Blueberry leaves have attracted attention as they are rich polyphenols such as proantocyanidins and chlorogenic acid. In this study, we investigated the effects of a high dose of blueberry leaf extract (BLEX) on alcohol metabolism during chronic intake of ethanol. Seven-week old Sprague-Dawley (SD) rats were divided into 4 groups: normal liquid diet group (NLD), normal liquid diet + BLEx group (NLD + BLEx), alcohol liquid diet group (ALD), and alcohol liquid diet + BLEx (ALD + BLEx). Then, rats were fed experimental diet for 5 weeks and at the end of feeding period, body weight, food intake, liver weight, indices of liver injury, expression and activity of alcohol metabolism-related and anti-oxidative enzymes, and levels of carbonyl protein, triglyceride (TG), and total cholesterol (T-Chol) were measured. Body weight and food intake decreased, whereas liver aldehyde dehydrogenase (ALDH) activity, liver microsomal cytochrome P450 2E1 (CYP2E1) protein and mRNA expression, and heme oxygenase 1 (HO-1) mRNA expression were upregulated by ethanol intake. Dietary BLEx, however, did not affect any of these ethanol-related changes. Indices of liver injury, expression and activity of other alcohol metabolism-related enzymes, liver carbonyl protein, TG, and T-Chol levels were not altered by ethanol and BLEx. Thus, chronic BLEx intake does not ameliorate the harmful effects of ethanol. 


\section{Chronic intake of high-dose of blueberry leaf extract} 2 does not augment the harmful effects of ethanol in

\section{3 rats}

4 Kaede Yamasaki ${ }^{1}$, Kazuhiro Sugamoto ${ }^{1}$, Teruaki Arakawa², Kazuo Nishiyama ${ }^{1}$ and Masao

5 Yamasaki ${ }^{1}$

61 Interdisciplinary Graduate School of Agriculture and Engineering, University of Miyazaki,

7 Miyazaki, Miyazaki, Japan

82 Bizen Chemical Company Limited, Akaiwa, Okayama, Japan

10 Corresponding Author:

11 Masao Yamasaki ${ }^{1}$

12 1-1 Gakuen Kibanadai-Nishi, Miyazaki, Miyazaki, 889-2192, Japan

13 Email address: myamasaki@cc.miyazaki-u.ac.jp 


\section{Chronic intake of high-dose of blueberry leaf extract 20 does not augment the harmful effects of ethanol in} 21 rats

22

23

24

25

26

27

28

29

30

31

32

33

34

35

36

37

38

39

40

41

42

43

44

45

46

47

48

49

50

51

52

53

54

55

Kaede Yamasaki ${ }^{1}$, Kazuhiro Sugamoto ${ }^{1}$, Teruaki Arakawa ${ }^{2}$, Kazuo Nishiyama ${ }^{1}$ and Masao Yamasaki $^{1}$

${ }^{1}$ Interdisciplinary Graduate School of Agriculture and Engineering, University of Miyazaki, Miyazaki, Miyazaki, Japan

${ }^{2}$ Bizen Chemical Company Limited, Akaiwa, Okayama, Japan

Corresponding Author:

Masao Yamasaki ${ }^{1}$

1-1 Gakuen Kibanadai-Nishi, Miyazaki, Miyazaki, 889-2192, Japan

Email address: myamasaki@cc.miyazaki-u.ac.jp

\section{Abstract}

Excessive alcohol consumption is a risk factor for liver diseases. Enhancement of alcohol metabolism could be an effective strategy to prevent these adverse effects since it promotes the clearance of ethanol and acetaldehyde from the serum. Polyphenol-rich products have shown to protect against alcohol-related liver damage. Blueberry leaves have attracted attention as they are rich polyphenols such as proantocyanidins and chlorogenic acid. In this study, we investigated the effects of a high dose of blueberry leaf extract (BLEx) on alcohol metabolism during chronic intake of ethanol. Seven-week old Sprague-Dawley (SD) rats were divided into 4 groups: normal liquid diet group (NLD), normal liquid diet + BLEx group (NLD + BLEx), alcohol liquid diet group (ALD), and alcohol liquid diet + BLEx (ALD + BLEx). Then, rats were fed experimental diet for 5 weeks and at the end of feeding period, body weight, food intake, liver weight, indices of liver injury, expression and activity of alcohol metabolism-related and anti-oxidative enzymes, and levels of carbonyl protein, triglyceride (TG), and total cholesterol (T-Chol) were measured. Body weight and food intake decreased, whereas liver aldehyde dehydrogenase (ALDH) activity, liver microsomal cytochrome P450 2E1 (CYP2E1) protein and mRNA expression, and heme oxygenase 1 (HO-1) mRNA expression were upregulated by ethanol intake. Dietary BLEx, however, did not affect any of these ethanol-related changes. Indices of liver injury, expression and activity of other alcohol metabolism-related enzymes, liver carbonyl protein, TG, and T-Chol levels were not altered by ethanol and BLEx. Thus, chronic BLEx intake does not ameliorate the harmful effects of ethanol. 
56

57

58

59

60

61

62

63

64

65

66

67

68

69

70

71

72

73

74

75

76

77

78

79

80

81

82

83

84

85

86

87

88

89

90

91

92

93

94

95

\section{Introduction}

Ethanol is metabolized to acetaldehyde by liver alcohol dehydrogenase (ADH) and liver microsomal cytochrome P450 2E1 (CYP2E1). It is further metabolized to acetic acid by liver mitochondrial aldehyde dehydrogenase (ALDH). Finally, acetic acid is decomposed into water and carbon dioxide by the tricarboxylic acid cycle and then excreted from the body (Zakhari, 2006). A substantial proportion of Asians, including Japanese, have mutations in the genes coding for ADH and ALDH resulting in an impaired ethanol metabolism (Eng et al., 2007). Thus, they often experience unpleasant side effects such as headache and nausea after excessive alcohol intake. The World Health Organization (WHO) has reported that alcohol abuse is the third leading risk factor for liver disease worldwide (WHO, 2009), and presented a "global strategy to reduce the harmful use of alcohol" in 2010 (WHO, 2010). Indeed, ethanol abuse substantially increases the risk of liver disease (Setshedi et al., 2010), acute lung injury (Kaphalia et al., 2013), and carcinogenesis (Seitz, Stickel, 2007). Enhancement of alcohol metabolism could be an effective strategy to prevent these effects since it promotes the clearance of ethanol and acetaldehyde from the serum. The metabolism of alcohol after chronic consumption has been shown to increase with noni juice containing a high concentration of proanthocyanidin, a class of polyphenol (Chang et al., 2013). Furthermore, resveratrol, which is also a polyphenol, alleviates alcoholic fatty liver by the upregulation of sirtuin 1 and adiponectin (Ajmo et al., 2008). Heme oxygenase 1 (HO-1) is one of the antioxidant enzymes and is upregulated in response to ethanol induced oxidative stress and additional upregulation of HO-1 results in alleviation of the hepatic oxidative stress. Actually, quercetin prevents the liver from acute alcoholic injury by upregulation of HO-1 (Liu et al., 2018). Thus, polyphenol-rich products have shown the potential to protect against alcohol-related liver damage. Blueberry leaves have attracted attention as it contains novel functional components, including quinic acid, proanthocyanidins, and several polyphenols (Matsuo et al., 2010). Further, blueberry leaves have been reported to exert protective effects against fatty liver (Yuji et al., 2013). It also has antifibrogenic (Takami et al., 2010) and suppressive effects on hepatitis C virus replication (Takeshita et al., 2009). We have confirmed that a single dose of blueberry leaf extract (BLEx) after single-dose ethanol reduces serum ethanol level (Yamasaki et al., 2016). From this previous data, we have hypothesized that BLEx could prevent the gastro intestinal absorption. The effect of chronic intake of a high dose of BLEx is, however, not clear. In this study to verify the safety of BLEx, we investigated the effects of high-dose BLEx on alcohol metabolism during chronic intake of ethanol.

\section{Materials \& Methods}

\section{Reagents}

BLEx was prepared as a hot water extract by Bizen Chemical Co. Ltd (Okayama, Japan). Briefly, blueberry leaf powder was extracted in 16 parts of hot water $\left(95-100^{\circ} \mathrm{C}\right)$ for $30 \mathrm{~min}$ twice. Then, the extract was filtered and heat sterilized. Finally, the extract was dried with a spray dryer, 
96 producing a powder. Ethanol was purchased from the Wako Pure Chemical Industries (Osaka,

97 Japan). The oxidized form of $\beta$-nicotinamide adenine dinucleotide hydrate (NADH), 4-

98 methylpyrazole, 2,4-dinitrophenylhydrazine, and trifluoroacetic acid (TFA) were purchased from

99 the Tokyo Chemical Industry (Tokyo, Japan).

100

101

\section{Ethanol intake model}

102

The animal studies were conducted in accordance with the Guide for the Care and Use of

103

104

105

106

107

108

109

110

111

112

113

114

115

116

117

118

119

120

121

122

123

124

125

126

127

128

129

130

131

132

133

134

135

Laboratory Animals of the University of Miyazaki (Animal Experiment Committee of Miyazaki University: 2017-014-2) and in compliance with the Law Concerning the Protection and Control of Animals (Japan Law No. 105), Standards Relating to the Care and Management of Laboratory Animals and Relief of Pain (Notification no. 88 of the Ministry of the Environment, Japan), and The Guidelines for Animals Experimentation (the Japanese Association for Laboratory Animal Science). The room temperature was maintained at $22-24^{\circ} \mathrm{C}$ and the animals were housed under a 12-h light/dark cycle (09:00-21:00).

Sprague-Dawley (SD) rats (all male, 7 weeks old, total 20) were purchased from Japan SLC (Hamamatsu, Japan) and acclimatized for 1 week. The rats were divided into 4 groups (5 per group): normal liquid diet group (NLD), normal liquid diet + BLEx group (NLD + BLEx), alcohol liquid diet group (ALD), and alcohol liquid diet + BLEx group (ALD + BLEx). The rats were fed with a Lieber-DeCarli liquid diet (Lieber at al. 1982). The composition of the liquid diet is shown in Table 1. Ethanol intake in the ALD group was gradually increased from $1 \%$ on day 1 to $5 \%$ over 7 days. $3 \%$ BLEx liquid diet was mixed with dry diet and the rats were fed for 5 weeks. After the end of the experiment, the rats were sacrificed using a mixture medetomidine (Kyoritsu Seiyaku Corporation, Tokyo, Japan), midazolam (Astellas Pharma Inc., Tokyo, Japan), and butorphanol (Meiji Seika Pharma Co., Ltd., Tokyo, Japan).

\section{Serum biochemical tests}

Serum alanine aminotransferase (ALT) and aspartate aminotransferase (AST) levels were estimated using Wako Transaminase CII-Test Kit (Wako). Serum total protein and albumin level and albumin/globulin (A/G) ratio were estimated using A/G B-Test Wako Kit (Wako).

\section{Liver aldehyde dehydrogenase (ADH) and alcohol dehydrogenase (ALDH) activities}

The liver tissues $(50 \mathrm{mg}$ ) were homogenized using $250 \mu \mathrm{l}$ of homogenized buffer $[0.25 \mathrm{M}$ sucrose, $5 \mathrm{mM}$ Tris, $0.5 \mathrm{mM}$ ethylenediaminetetraacetic acid (EDTA)-2Na, and $2 \mathrm{mM} 2$ mercaptoethanol]. The homogenates were centrifuged $\left(13,000 \times \mathrm{g}\right.$ for 10 min at $\left.4^{\circ} \mathrm{C}\right)$ and the supernatant was collected. Ten-fold diluted supernatant $(25 \mu \mathrm{l})$ was mixed with ADH reaction assay buffer [ $225 \mu 1,5 \mathrm{mM}$ NADH, $5 \mathrm{mM}$ ethanol, $9 \mathrm{mM}$ glycine, and $120 \mathrm{mM}$ sodium pyrophosphate ( $\mathrm{pH} 8.8)]$ or ADH negative assay buffer [( $225 \mu \mathrm{l}, 5 \mathrm{mM} \mathrm{NADH}, 1 \mathrm{mM} 4-$ methylpyrazole, $9 \mathrm{mM}$ glycine, and $120 \mathrm{mM}$ sodium pyrophosphate ( $\mathrm{pH} 8.8)$ ] in a 96-well plate. To determine ALDH activity, $25 \mu \mathrm{l}$ of 10 -fold diluted supernatant was mixed with $225 \mu \mathrm{l}$ of ALDH reaction assay buffer [0.5 mM NADH, $10 \mathrm{mM}$ acetaldehyde, $0.1 \mathrm{mM}$ 4-methylpyrazole, 
$1362 \mu \mathrm{M}$ rotenone, and $60 \mathrm{mM}$ sodium pyrophosphate ( $\mathrm{pH} \mathrm{8.8)]} \mathrm{or} 225 \mu \mathrm{l}$ ALDH negative assay

137 buffer [0.5 mM NADH, $0.1 \mathrm{mM} 4$-methylpyrazole, $2 \mu \mathrm{M}$ rotenone, and $60 \mathrm{mM}$ sodium

138 pyrophosphate $(\mathrm{pH} 8.8)]$ in a 96-well plate. The change in absorbance $(340 \mathrm{~nm})$ was measured

139 by a plate reader at $0,3,6,9,12$, and $15 \mathrm{~min}$. The protein level was estimated by using a

140 commercial Pierce ${ }^{\circledR}$ Bicinchoninic Acid (BCA) Protein Assay Kit (Thermo). The liver ADH and

141 ALDH activities were calculated by the following equation: $\mathrm{ADH}$ and ALDH activity $=(\triangle \mathrm{A} / \mathrm{min}$

$142 \times \mathrm{V} \times \mathrm{D}) /(6.3 \times \mathrm{d} \times \mathrm{v})$, where, $\Delta \mathrm{A} / \mathrm{min}$ is the change in absorbance at $340 \mathrm{~nm}, \mathrm{~V}$ is the final

143 volume, $\mathrm{D}$ is the dilution rate, 6.3 is the molecular extinction coefficient at $1 \mathrm{mM}$ of NADH at

$144340 \mathrm{~nm}, \mathrm{~d}$ is the optical path length, and $\mathrm{v}$ is the sample volume.

145

146

147

148

149

150

151

152

153

154

155

156

157

158

159

160

161

162

163

164

165

166

167

168

169

170

171

172

173

174

175

\section{Fractionation of the liver microsomal fraction}

The liver tissues $(2 \mathrm{~g})$ were homogenized using $10 \mathrm{ml}$ of homogenized buffer [ $250 \mathrm{mM}$ sucrose, $75 \mathrm{mM}$ nicotinamide, $2.5 \mathrm{mM}$ EDTA-2Na, $20 \mathrm{mM}$ 2-mercaptoethanol, and $50 \mathrm{mM}$ potassium phosphate buffer ( $\mathrm{pH}$ 7.4)]. Following that, the homogenates were centrifuged at $12,425 \times \mathrm{g}$ for $20 \mathrm{~min}$ at $4^{\circ} \mathrm{C}$ and the supernatants were ultracentrifuged at $109,572 \times \mathrm{g}$ for $1 \mathrm{~h}$ at $4^{\circ} \mathrm{C}$. After the supernatant was discarded, the pellets were redissolved in $2 \mathrm{ml}$ of dissolution buffer $[5 \mathrm{mM}( \pm)$ dithiothreitol and $20 \mathrm{mM}$ potassium phosphate buffer ( $\mathrm{pH}$ 7.4)].

\section{Western blot}

The microsomal fraction was lysed with $50 \mathrm{mM}$ Tris- $\mathrm{HCl}(\mathrm{pH} 7.5)$ containing $150 \mathrm{mM} \mathrm{NaCl}$, $2 \%$ Triton X-100, 2 mM EDTA, $50 \mathrm{mM} \mathrm{NaF}$, and $30 \mathrm{mM} \mathrm{Na}_{4} \mathrm{P}_{2} \mathrm{O}_{7}$ with $1 / 50$ volume of a protease inhibitor cocktail (Nacalai Tesque, Kyoto, Japan). The protein levels were estimated using a BCA protein assay reagent (Pierce, Rockford, IL). The lysate containing $1 \mu \mathrm{g}$ of protein was denatured and separated by electrophoresis on a $10 \%$ sodium dodecyl sulfatepolyacrylamide gel and transferred onto Hybond $\mathbb{R}-\mathrm{P}$ polyvinylidene fluoride (PVDF) membranes (GE Healthcare, Buckinghamshire, UK). The nonspecific sites were blocked by incubating the membrane with 3\% non-fat dried milk in Tris-buffered saline and $0.1 \%$ Tween-20 (T-TBS) for $60 \mathrm{~min}$ at a room temperature. The antibodies were diluted with Can Get Signal solutions 1 and 2 (TOYOBO, Tokyo, Japan). CYP2E1 specific polyclonal antibody was purchased from Proteintech Group, Inc. (IL, USA). Horseradish peroxidase-conjugated antirabbit IgG was purchased from Cell Signaling Technology® (Cell Signaling Technology, Inc., MA, USA). Following each antibody binding reaction, the membranes were washed with T-TBS. The proteins on the membrane were detected using ImageQuant LAS 4000 (GE Healthcare). The band intensity was quantified using ImageQuant TL (GE Healthcare) and the representative blot patterns are shown.

\section{Isolation of RNA, reverse-transcription of RNA, and real-time polymerase chain reaction (PCR)}

The total RNA was isolated from the liver using TRIzol reagent (Thermo Fisher Scientific Inc., MA, USA). Rever Tra Ace qPCR RT Kit (TOYOBO) was used to synthesize cDNA. Real-time 
176 PCR was performed with an Agilent AriaMx Real-Time PCR System (Agilent Technologies, 177 Inc., CA, USA) using THUNDERBIRD ${ }^{\circledR}$ SYBR ${ }^{\circledR}$ qPCR Mix (TOYOBO). The temperature was 178 controlled according to the manufacturer's instructions. The primer sequences for the real-time 179 PCR are listed in Table 2. To quantify mRNA expression, the data obtained by real-time PCR 180 were analyzed according to the Praffl method. Expression of $\beta$-actin, a housekeeping gene was 181 estimated to normalize the expression of the target genes.

182

183

184

\section{Estimation of liver carbonyl protein}

The liver carbonyl protein assay was performed according to the method described by Colombo et al. (Colombo et al., 2016). The liver tissues (100 mg) were homogenized using $1 \mathrm{ml}$ phosphate buffered saline (PBS), the homogenates were centrifuged $\left(12,000 \times \mathrm{g}\right.$ for $15 \mathrm{~min}$ at $\left.4^{\circ} \mathrm{C}\right)$, and the supernatant was collected. The protein level in the supernatant was determined using a BCA protein assay reagent. The supernatant was diluted to a concentration of $1 \mathrm{mg} / \mathrm{ml} .500 \mu 1$ of the diluted supernatant was mixed with $100 \mu \mathrm{l}$ of $10 \mathrm{mM}$ 2,4-dinitrophenylhydrazine (DNPH)-(2N) $\mathrm{HCl}$ and incubated for $1 \mathrm{~h}$ at a room temperature with shaking.

The final sample was mixed with ice-cold $20 \%$ perchloric acid $(600 \mu 1)$ and then incubated for $15 \mathrm{~min}$ on ice. Following that, the samples were centrifuged $(10,000 \times \mathrm{g}$ for $5 \mathrm{~min}$ at $4^{\circ} \mathrm{C}$ ) and the pellets were collected. The pellets were mixed with ice-cold $20 \%$ perchloric acid $(500 \mu \mathrm{l})$ and again centrifuged $\left(10,000 \times \mathrm{g}\right.$ for $5 \mathrm{~min}$ at $\left.4^{\circ} \mathrm{C}\right)$. Subsequently, the pellets were collected and mixed with 1:1 (v/v) ethanol-ethyl acetate. They were again centrifuged $(10,000 \times$ $\mathrm{g}$ for $5 \mathrm{~min}$ at $4^{\circ} \mathrm{C}$ ) and the final pellets were collected. This process of mixing ethanol-ethyl acetate and centrifugation was repeated.

The obtained pellets were mixed with $250 \mu \mathrm{l}$ of $0.2 \%$ (w/v) SDS in $20 \mathrm{mM}$ Tris- $\mathrm{HCl}(\mathrm{pH}$ 6.8) and incubated at $95^{\circ} \mathrm{C}$ for $10 \mathrm{~min}$. The pellets were then homogenized by ultrasonication and the protein content was determined by BCA protein assay. Western blot was performed with the sample. The samples containing $1 \mu \mathrm{g}$ of protein were denatured. Anti-DNPH was purchased from Thermo fisher scientific Inc. (MA, USA).

\section{Estimation of liver triglyceride (TG) and total cholesterol (T-Chol) levels}

The liver tissues $(200 \mathrm{mg}$ ) were homogenized using $1 \mathrm{ml}$ of PBS, the homogenates were centrifuged $\left(12,000 \times \mathrm{g}\right.$ for $15 \mathrm{~min}$ at $\left.4^{\circ} \mathrm{C}\right)$, and the supernatant was collected. Liver TG and TChol levels were determined using Triglyceride E-Test Wako (Wako) and Cholesterol E-Test Wako (Wako), respectively.

\section{Statistical analysis}

Initially, the data were analyzed using two-way analysis of variance (ANOVA) to identify the effects of alcohol, BLEx, and their interaction. When the interaction was significant, the data were analyzed using the Tukey-Kramer test. The analyses were conducted using Statcel3 software (OMS Publishing, Saitama, Japan). A p value of $<0.05$ was considered as statistically significant. 


\section{Results}

218

219

220

221

222

223

224

225

226

227

228

229

230

231

232

233

234

235

236

237

238

239

240

241

242

243

244

245

246

247

248

249

250

251

252

253

254

255

\section{Effects of BLEx on body weight, food intake, and liver weight}

As shown in Fig. 1, final body weight and food intake in the alcohol intake groups were significantly lower than the non-alcohol intake groups. No significant difference was, however, noted between the non-BLEx intake and BLEx intake groups. The liver weight was unchanged by alcohol and BLEx intake.

\section{Effects of BLEx on indices of alcoholic liver injury}

The levels of serum AST, ALT, albumin, total protein, AST/ALT ratio, and A/G ratio in rats are shown in Fig. 2. As shown in Fig. 2A-2C, the serum ALT level in alcohol intake groups was significantly higher than the non-alcohol intake groups. The serum AST level and the ratio of AST/ALT, however, were not changed by alcohol and BLEx. As shown in Fig. 2D-2F, no significant difference was found among the experimental groups.

\section{Effects of BLEx on level or expression of protein and mRNA related to alcohol metabolism} in the liver

The liver ADH and ALDH activities in the rats are shown in Fig. 3A and 3B. The liver ADH activity was unchanged by alcohol and BLEx (Fig. 3A). The liver ALDH activity, however, significantly increased in the alcohol intake groups as compared to the non-alcohol intake groups. However, the ALDH activity was not changed by BLEx intake (Fig. 3B).

The liver ADH1 and ALDH2 mRNA expression in the rats are shown in Fig. 3C and 3D. Liver ADH1 mRNA expression was significantly changed by BLEx intake. Liver ALDH2 mRNA expression was not changed by alcohol and BLEx. Liver CYP2E1 protein and mRNA expression levels are shown in Fig. 3E-3G. As shown in Fig. 3E and 3F, liver CYP2E1 protein expression significantly increased in the ALD and ALD + BLEx groups as compared to the NLD and NLD + BLEx groups, respectively. No significant difference in the liver CYP2E1 protein expression was, however, noted between the ALD and ALD + BLEx groups. As shown in Fig. 3G, the liver CYP2E1 mRNA expression was significantly higher in the alcohol intake groups as compared to the non-alcohol intake groups. However, the CYP2E1 mRNA expression was not changed by BLEx.

\section{Effects of BLEx on liver carbonyl protein level and HO-1 mRNA expression in the liver} As shown in Fig. 4A, the liver carbonyl protein level was not changed by alcohol and BLEx. As shown in Fig. 4B, the HO-1 mRNA expression in the liver was significantly increased in the alcohol intake groups as compared to the non-alcohol intake groups.

\section{Effects of BLEx on liver TG and T-Chol levels in the liver}

As shown in Fig. 5A and 5B, the TG and T-Chol levels in the liver were not changed by alcohol and BLEx. 
257

258

259

260

261

262

263

264

265

266

267

268

269

270

271

272

273

274

275

276

277

278

279

280

281

282

283

284

285

286

287

288

289

290

291

292

293

294

295

\section{Discussion}

Our previous study has investigated the effects of single-dose BLEx ( $1 \mathrm{~g} / \mathrm{kg}$ body weight) on alcohol metabolism and absorption of ethanol in single-dose ethanol intake rat (Yamasaki et al., 2016). We have previously done study in which $1 \mathrm{~g}$ BLEx significantly prevented elevation of serum ethanol and acetaldehyde levels after $0.5 \mathrm{~g} / \mathrm{kg}$ body weight ethanol intake (M Yamasaki, 2015, unpublished data). In this study, we have investigated the effects of high-dose BLEx on alcohol metabolism in chronic ethanol intake rats. Our concerns in this study is the synergistic adverse effects of ethanol and BLEx as is some natural plant extracts regulated the expression of CYPs. For instance, extract of Ginkgo biloba upregulated CYP2E1 expression (Sugiyama et al., 2004). Information for the synergistic effect on detoxication metabolism may be an important for the prevention of the adverse effects. Based on our previous single dose studies, we set the dose of 3\% BLEx. The animal model was created according to the methods described by ReyesGordillo et al. (Reyes-Gordillo et al., 2016). The serum AST, ALT, total protein, albumin levels, and $\mathrm{A} / \mathrm{G}$ ratio, which are the indices of liver injury did not change when the rats were fed with $5 \%$ ethanol for 5 weeks, demonstrating that there was no ethanol-induced liver injury. This further signified that the amount and duration of ethanol intake were not enough to induce liver injury. A previous study has shown that alcohol intake did not affect liver weight (Yun et al., 2007), but it reduced the body weight (Rouach et al., 2005). The results of our study are similar to those in this study.

Although BLEx prevented the gain in body weight, the alcohol-induced reduction in body weight was not affected by BLEx. This indicated that BLEx did not affect alcohol-induced body weight reduction. A previous study has shown that the food intake in 4 week-old SD rats was reduced by 8 weeks intake of ethanol (Kim et al., 2014). In this study, BLEx did not affect the alcohol-induced reduction in food intake. Taken together, we have shown that a long-term BLEx intake does not affect alcohol-induced change in the food intake and body composition.

In this study, we have also investigated the effects of BLEx on ADH, ALDH, and CYP2E1, which are responsible for alcohol metabolism in the liver (Zakhari, 2006). There was a greater change in the CYP2E1 expression than the liver ADH and ALDH activities. The results are similar to a previous study which showed that CYP2E1 expression was increased by longterm alcohol intake (Cederbaum, 2010). CYP2E1 protein and mRNA expression were, however, not changed by BLEx in this study. The polyphenol level of BLEx was $403 \mathrm{mg} / \mathrm{g}$ equivalent tannic acid, whereas, the polyphenol level of the liquid diet was $1.598 \mathrm{~g} / \mathrm{L}$.

The effects of dietary polyphenol on CYP2E1 regulation has been reported. The administration of red wine containing $350 \mathrm{mg}$ polyphenol/L for 9 weeks to SD rats increased CYP2E1 protein expression (Cowpland, 2006). On the contrary, administration of red wine containing $55.2 \mathrm{mg}$ total flavonols/L to Wister rats for 10 weeks inhibited alcohol-induced CYP2E1 protein expression (Orellana, 2002). It was also demonstrated that an intake of $3 \mathrm{~g} / \mathrm{L}$ of dietary epigallocatechin-3-gallate did not affect the alcohol-induced increase in CYP2E1 protein expression (Yun et al., 2007). The human equivalent dose of BLEx used in this study $(1.69 \mathrm{~g} / \mathrm{kg}$ ) 
296

297

298

299

300

301

302

303

304

305

306

307

308

309

310

311

312

313

314

315

316

317

318

319

320

321

322

323

324

325

326

327

328

329

330

331

332

333

334

335

(HHS et al., 2005) was very high. In addition, the polyphenol content in the liquid diet (1.60 g/L) was also much higher than used in other studies. BLEx, however, did not affect alcohol-induced increased CYP2E1 protein and mRNA expression in the liver.

Proanthocyanidins (11.34\%) is present in the blueberry leaves (Matsuo et al., 2010). When experimental rats were administered $12.6 \mathrm{mg} / \mathrm{kg}$ proanthocyanidins for 5 days, the liver CYP2E1 activity was found to be unchanged (Sugiyama et al., 2004). This study shows that chronic intake of a high dose BLEx did not affect liver CYP2E1 expression. In this study, liver ADH activity and ADH1 and ALDH2 mRNA expression were not changed by alcohol intake, although the liver ALDH activity was significantly increased. Similar findings were previously reported by other authors (Kishimoto et al., 1995). The liver ADH and ALDH activities and ADH1 and ALDH2 mRNA expression, however, were unchanged by BLEx. A previous study has shown alcohol/dextrose meal intake decreases blood ethanol due to impairment of gastric emptying (Kaufman \& Kaye, 1979). In addition, grape-seed proanthocyanidin delays gastric emptying in rat (Serrano et al., 2016). Our previous study shown that BLEx could be useful for preventing alcohol-related disorders by inhibiting ethanol absorption (Yamasaki et al., 2016). Thus, BLEx might modulate alcohol absorption through delaying gastric emptying. Therefore, long-term intake of a high dose of BLEx does not affect alcohol metabolism in the liver.

Alcohol-related oxidative stress in the liver is caused by CYP2E1 (Koop, 2006), while alcoholic liver steatosis is caused by oxidative stress (Yang et al., 2012). Because of the oxidative stress, HO-1 mRNA expression and activity are increased by augmenting CYP2E1 expression. In this study, we have found that the HO-1 mRNA and CYP2E1 protein and mRNA expression in the liver were upregulated by chronic alcohol intake.

The carbonyl protein level in the liver also increases due to alcohol-related oxidative stress (Galligan, 2012; Jayaraman, 2009). In this study, we have found that liver carbonyl protein level was unchanged by alcohol, signifying that alcohol did not result in an oxidative stress because of sufficient anti-oxidant reserve. Several reports have shown that anti-oxidative protein expression can be induced by polyphenols. Dietary tea polyphenols were found to improve alcohol-induced rise in serum malondialdehyde level and decrease in serum superoxide dismutase level in rats with ethanol-induced liver fibrosis (Li et al., 2004). In addition, HO-1 protein and gene expression was found to be significantly increased by chlorogenic acid in a dose-dependent manner (Shi et al., 2018). Since dietary BLEx did not change liver HO-1 mRNA expression in this study, it can be concluded that a high dose of BLEx does not affect antioxidant reserve in spite of CYP2E1 induction by ethanol.

Previous studies have shown that alcoholic liver steatosis could develop due to increased CYP2E1 expression ( $\mathrm{Lu}, 2008,2010$; Ceni et al., 2014). In this study, although liver CYP2E1 protein and mRNA levels were increased by alcohol, liver TG and T-Chol levels were not changed. Therefore, alcoholic liver steatosis was not induced by ethanol. In addition, since BLEx feeding did not change the liver TG and T-Chol levels, we inferred that a high dose of BLEx does not affect the liver lipid store. 


\section{Conclusions}

337 Chronic alcohol intake increased the liver CYP2E1 and anti-oxidative protein expression without

338

339

340

341

342

343

344

345

346

347

348

349

350

351

352

353

354

355

356

357

358

359

360

361

362

363

364

365

366

367

368

369

370

371

372

373

374

inducing alcohol-related oxidative stress and alcoholic liver steatosis. A chronic high-dose of BLEx did not augment the harmful effects of ethanol.

\section{References}

Ajmo JM, Liang X, Rogers CQ, Pennock B, You M. 2008. Resveratrol alleviates alcoholic fatty liver in mice. American Journal of Physiology. Gastrointestinal and Liver Physiology 295:833842 DOI: 10.1152/ajpgi. 90358.2008

Cederbaum AI. 2010. Role of CYP2E1 in ethanol-induced oxidant stress, fatty liver and hepatotoxicity. Digestive Diseases 28:802-811 DOI: 10.1159/000324289

Ceni E, Mello T, Galli A. 2014. Pathogenesis of alcoholic liver disease: role of oxidative metabolism. World Journal of Gastroenterology 20:17756-17772 DOI:

10.3748/wjg.v20.i47.17756

Chang YY, Lin YL, Yang DJ, Liu CW, Hsu CL, Tzang BS, Chen YC. 2013. Hepatoprotection of noni juice against chronic alcohol consumption: lipid homeostasis, antioxidation, alcohol clearance, and anti-inflammation. Journal of Agriculture and Food Chemistry 61:11016-11024 DOI: $10.1021 / \mathrm{jf} 4038419$

Colombo G, Clerici M, Garavaglia ME, Giustarini D, Rossi R, Milzani A, Dalle-Donne I. 2016. A step-by-step protocol for assaying protein carbonylation in biological samples. Journal of Chromatography. B, Analytical Technologies in the Biomedical and Life Sciences 1019:178-190 DOI: 10.1016/j.jchromb.2015.11.052

Cowpland C, Su GM, Murray M, Puddey IB, Croft KD. 2006. Effect of alcohol on cytochrome p450 arachidonic acid metabolism and blood pressure in rats and its modulation by red wine polyphenolics. Clinical and Experimental Pharmacology \& Physiology 33:183-188

Eng MY, Luczak SE, Wall TL. 2007. ALDH2, ADH1B, and ADH1C genotypes in asians: a literature review. Alcohol Research \& Health: the Journal of the National Institute on Alcohol Abuse and Alcoholism. 30:22-27

Galligan JJ, Smathers RL, Fritz KS, Epperson LE, Hunter LE, Petersen DR. 2012. Protein carbonylation in a murine model for early alcoholic liver disease. Chemical Research in Toxicology 25:1012-1021 DOI: 10.1021/tx300002q

Gao B, Bataller R. 2011. Alcoholic liver disease: pathogenesis and new therapeutic targets Gastroenterology 141:1572-1585 DOI: 10.1053/j.gastro.2011.09.002

Jayaraman J, Veerappan M, Namasivayam N. 2009. Potential beneficial effect of naringenin on lipid peroxidation and antioxidant status in rats with ethanol-induced hepatotoxicity. Journal of Pharmacy and Pharmacology 61:1383-1390 DOI: 10.1211/jpp/61.10.0016.

Kaphalia L, Calhoun WJ. 2013. Alcoholic lung injury: metabolic, biochemical and immunological aspects. Toxicology Letters 222:171-179 DOI: 10.1016/j.toxlet.2013.07.016 Kaufman SE, Kaye MD. 1979. Effect of ethanol upon gastric emptying. Gut 20:688-692 
375 Kim MJ, Sim MO, Lee HI, Ham JR, Seo KI, Lee MK. 2014. Dietary umbelliferone attenuates 376 alcohol-induced fatty liver via regulation of PPAR $\alpha$ and SREBP-1c in rats. Alcohol 48:707-715 377 DOI: 10.1016/j.alcohol.2014.08.008

378 Kishimoto R, Fujiwara I, Kitayama S, Goda K, Nakata Y. 1995. Changes in hepatic enzyme 379 activities related to ethanol metabolism in mice following chronic ethanol administration.

380 Journal of Nutritional Science and Vitaminology 41:527-543

381 Koop DR. 2006. Alcohol metabolism's damaging effects on the cell: a focus on reactive oxygen 382 generation by the enzyme cytochrome P450 2E1. Alcohol Research \& Health: the Journal of the 383 National Institute on Alcohol Abuse and Alcoholism 29:274-280

384 Li YM, Zhang XG, Zhou HL, Chen SH, Zhang Y, Yu CH. 2004. Effects of tea polyphenols on 385 hepatic fibrosis in rats with alcoholic liver disease. Hepatobilliary \& Pancreatic Diseases International: HBPD INT 3:577-579

387

388

389

390

391

392

393

394

395

396

397

398

399

400

401

402

403

404

405

406

407

408

409

410

411

412

413

Lieber CS, DeCarli LM. 1982. The feeding of alcohol in liquid diets: two decades of applications and 1982 update. Alcoholism, Clinical and Experimental Research 6:523-531

Liu S, Tian L, Chai G, Wen B, Wang B. 2018. Targeting neme oxygenase-1 by quercetin ameliorates alcohol-induced acute liver injury via inhibiting NLRP3 inflammasome activation. Food \& Function 9:4184-4193 DOI: 10.1039/c8fo00650d

Lu Y, Wu D, Wang X, Ward SC, Cederbaum AI. 2010. Chronic alcohol-induced liver injury and oxidant stress are decreased in cytochrome P4502E1 knockout mice and restored in humanized cytochrome P4502E1 knock-in mice. Free Radical Biology \& Medicine 49:1406-1416 DOI: 10.1016/j.freeradbiomed.2010.07.026

Lu Y, Zhuge J, Wang X, Bai J, Cederbaum AI. 2008. Cytochrome P450 2E1 contributes to ethanol-induced fatty liver in mice. Hepatology 47:1483-1494 DOI: 10.1002/hep.22222 Matsuo Y, Fujita Y, Ohnishi S, Tanaka T, Hirabaru H, Kai T, Sakaida H, Nishizono S, Kouno I. 2010. Chemical constituents of the leaves of rabbiteye blueberry (Vaccinium ashei) and characterization of polymeric proanthocyanidins containing phenylpropanoid units and A-type linkages. Food Chemistry 121:1073-1079 DOI: 10.1016/j.foodchem.2010.01.052

Orellana M, Varela N, Guajardo V, Araya J, Rodrigo R. 2002. Modulation of rat liver cytochrome $\mathrm{P} 450$ activity by prolonged red wine consumption. Comparative Biochemistry and Physiology. Toxicology \& Pharmacology: CBP 131:161-166

Reyes-Gordillo K, Shah R, Varatharajalu R, Garige M, Leckey LC, Lakshman MR. 2016. Low$\omega 3$ Fatty Acid and Soy Protein Attenuate Alcohol-Induced Fatty Liver and Injury by Regulating the Opposing Lipid Oxidation and Lipogenic Signaling Pathways. Oxidative Medicine and Cellular Longevity 2016:1-11 DOI: 10.1155/2016/1840513

Rouach H, Andraud E, Aufrère G, Beaugé F. 2005. The effects of acetaldehyde in vitro on proteasome activities and its potential involvement after alcoholization of rats by inhalation of ethanol vapours. Alcohol and Alcoholism 40:359-366

Seitz HK, Stickel F. 2007. Molecular mechanisms of alcohol-mediated carcinogenesis. Nature Reviews. Cancer 7:599-612 
414 Serrano J, Casanova-Marti A, Gil-Cardoso K, Blay MT, Terra X, Pinent M, Ardevol A. 2016. 415 Acutely administered grape-seed proanthocyanidin extract acts as a satiating agent. Food \& 416 Function 7:483-490 DOI: 10.1039/c5fo00892a

417 Setshedi M, Wands JR, Monte SM. 2010. Acetaldehyde adducts in alcoholic liver disease.

418 Oxidative Medicine and Cellular Longevity 3:178-185 DOI: 10.4161/oxim.3.3.3

419 Shi A, Shi H, Wang Y, Liu X, Cheng Y, Li H, Zhao H, Wang S, Dong L. 2018. Activation of 420 Nrf2 pathway and inhibition of NLRP3 inflammasome activation contribute to the protective

421 effect of chlorogenic acid on acute liver injury. International Immunopharmacology 54:125-130 422 DOI: 10.1016/j.intimp.2017.11.007

423 Sugiyama T, Shinozuka K, Sano A, Yamada S, Endoh K, Yamada K, Umegaki K. 2004. Effects 424 of various ginkgo biloba extracts and proanthocyanidin on hepatic cytochrome P450 activity in 425 rats. Shokuhin Eiseigaku Zasshi. Journal of the Food Hygienic Society of Japan 45:295-301 426 DOI: 10.3358/shokueishi.45.295

427 Takami Y, Uto H, Takeshita M, Kai H, Akamatsu E, Moriuchi A, Hasegawa S, Oketani M, Ido 428 A, Kataoka H, Tsubouchi H. 2010. Proanthocyanidin derived from the leaves of Vaccinium 429 virgatum suppresses platelet-derived growth factor-induced proliferation of the human hepatic 430 stellate cell line LI90. Hepatology Research: the Official Journal of the Japan Society of 431 Hepatology 40:337-345 DOI: 10.1111/j.1872-034X.2009.00589.x

432 Takeshita M, Ishida Y, Akamatsu E, Ohmori Y, Sudoh M, Tsubouchi H, Kataoka H. 2009.

433 Proanthocyanidin from blueberry leaves suppresses expression of subgenomic hepatitis $\mathrm{C}$ virus 434 RNA. The Journal of Biological Chemistry 284:21165-21176 DOI: 10.1074/jbc.M109.004945

435 U.S. Department of Health and Human Services (HHS), Food and Drug Administration (FDA), 436 Center for Drug Evaluation and Research (CDER) (USA). 2005. Guidance for industry 437 estimating the maximum safe starting dose in initial clinical trials for therapeutics in adult 438 healthy volunteers. Pharmacology and Toxicology.

439 World Health Organization (WHO) (Switzerland). 2009. Global health risks: mortality and 440 burden of disease attributable to selected major risks.

441 World Health Organization (WHO) (Switzerland). 2010. Global strategy to reduce the harmful 442 use of alcohol.

443 Yamasaki K, Nagatomo H, Kawamura Y, Sugamoto K, Kai T, Kamenaga K, Takeshita M, 444 Kikushi Y, Matsuura Y, Yukizaki C, Nishiyama K, Yamasaki M. 2016. A single dose of 445 blueberry leaf extract suppresses serum ethanol levels after oral ethanol administration in rats.

446 European Journal of Scientific Research 140:352-365

447 Yang L, Wu D, Wang X, Cederbaum AI. 2012. Cytochrome P4502E1, oxidative stress, JNK, 448 and autophagy in acute alcohol-induced fatty liver. Free Radical Biology \& Medicine 53:1170449 1180 DOI: 10.1016/j.freeradbiomed.2012.06.029

450 Yuji K, Sakaida H, Kai T, Fukuda N, Yukizaki C, Sakai M, Tsubouchi H, Kataoka H. 2013.

451 Effect of dietary blueberry (Vaccinium ashei Reade) leaves on serum and hepatic lipid levels in 452 rats. Journal of Oleo Science 62:89-96 DOI: 10.5650/jos.62.89 
453 Yun JW, Kim YK, Lee BS, Kim CW, Hyun JS, Baik JH, Kim JJ, Kim BH. 2007. Effect of 454 dietary epigallocatechin-3-gallate on cytochrome P450 2E1-dependent alcoholic liver damage:

455 enhancement of fatty acid oxidation. Bioscience, Biotechnology, and Biochemistry 71:2999-3006 456 DOI: $10.1271 / \mathrm{bbb} .70403$

457 Zakhari S. 2006. Overview: How is alcohol metabolized by the body? Alcohol Research \& 458 Health: the Journal of the National Institute on Alcohol Abuse and Alcoholism 29:245-254 
Figure 1

Body weight, food intake and liver weight.

(A) Changes in body weight, (B) final body weight, (C) food intake change, (D) daily food intake, and $(E)$ liver weight in rats $(n=5)$. The values are expressed as the mean $\pm S D$. 
A

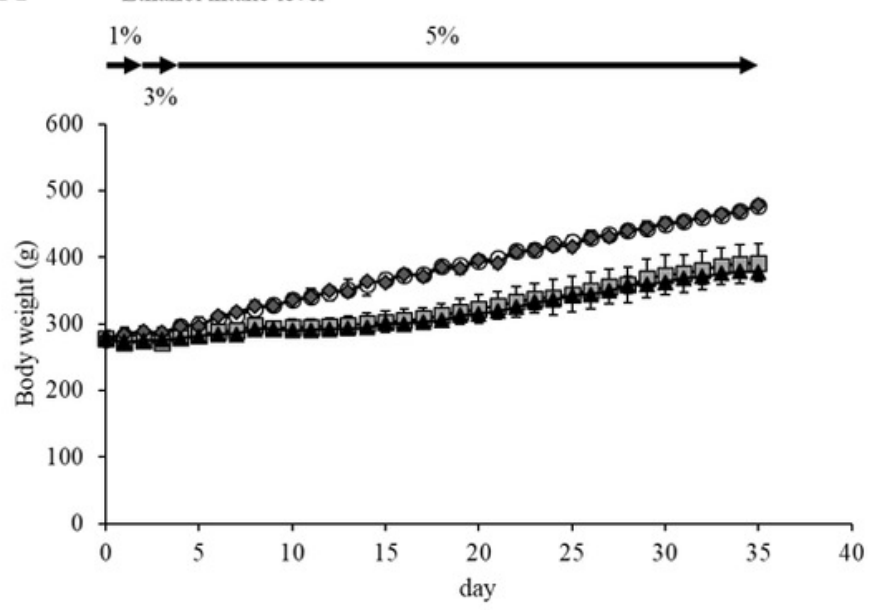

$\multimap-\mathrm{NLD} \rightarrow-\mathrm{ALD} \rightarrow \mathrm{NLD}+\mathrm{BLEx} \quad \nrightarrow$ ALD + BLEx

C

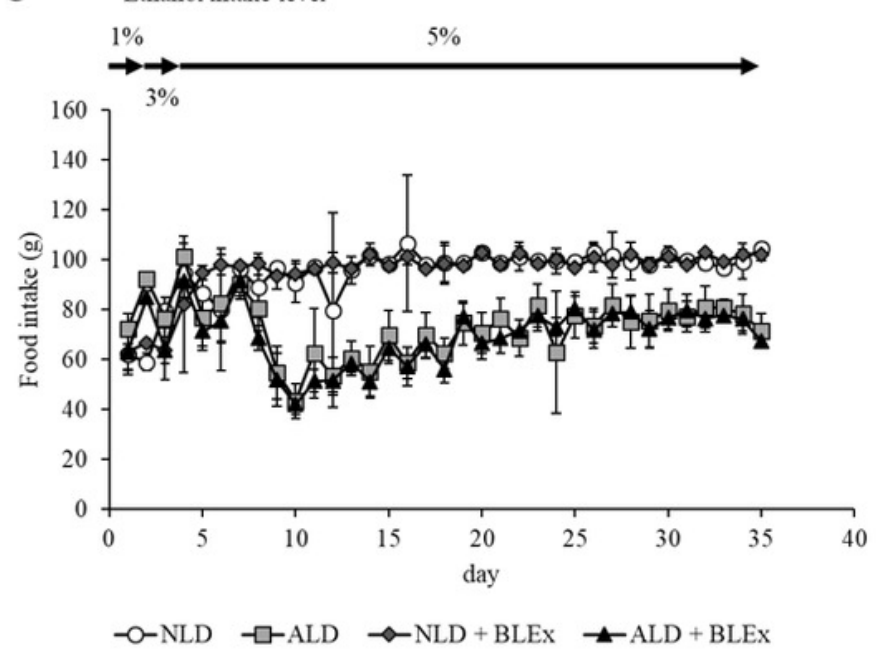

$\mathrm{E}$

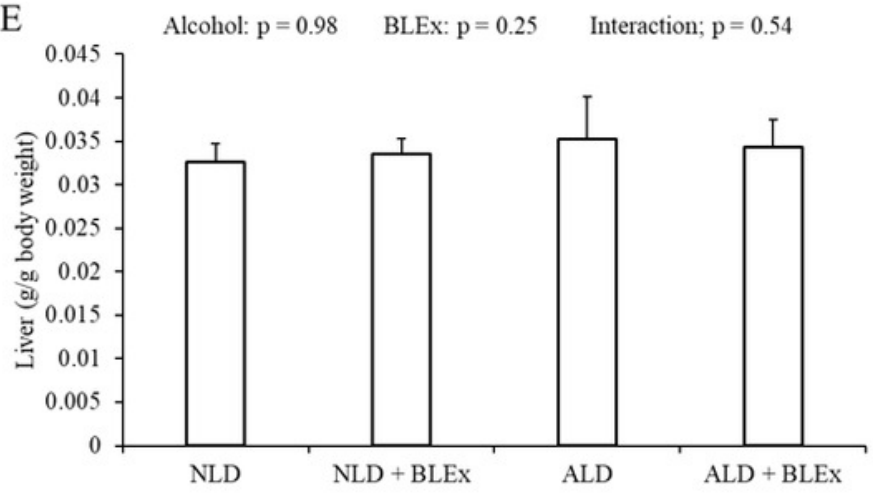

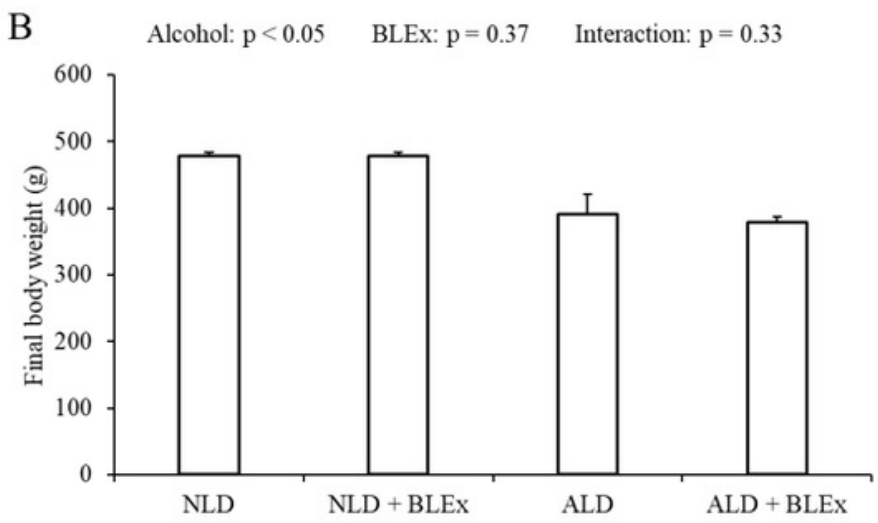

D Alcohol: $\mathrm{p}<0.05$ BLEx: $\mathrm{p}=0.45$ Interaction: $\mathrm{p}=0.25$

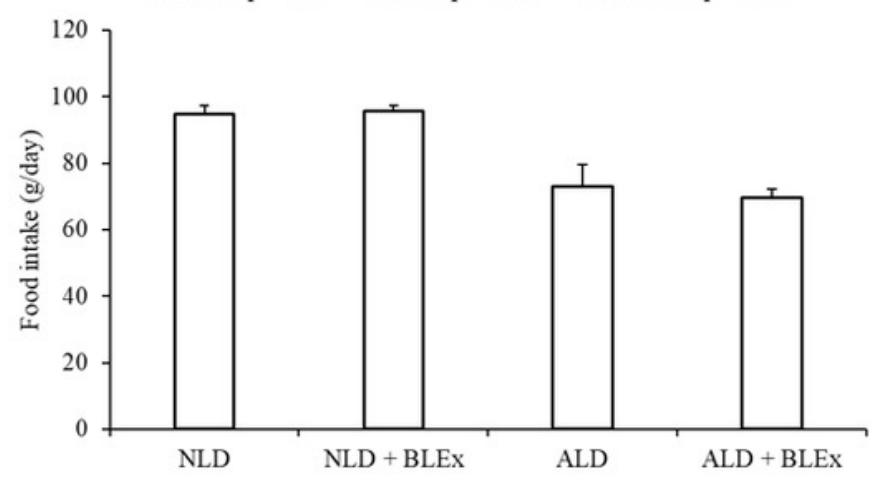


Figure 2

Indices of alcoholic liver injury.

(A) Serum AST level, (B) ALT level, (C) AST/ALT ratio, (D) albumin level, (E) total protein level, and $(F)$ albumin/globulin ratio in rats $(n=5)$. The values are expressed as the mean $\pm S D$.
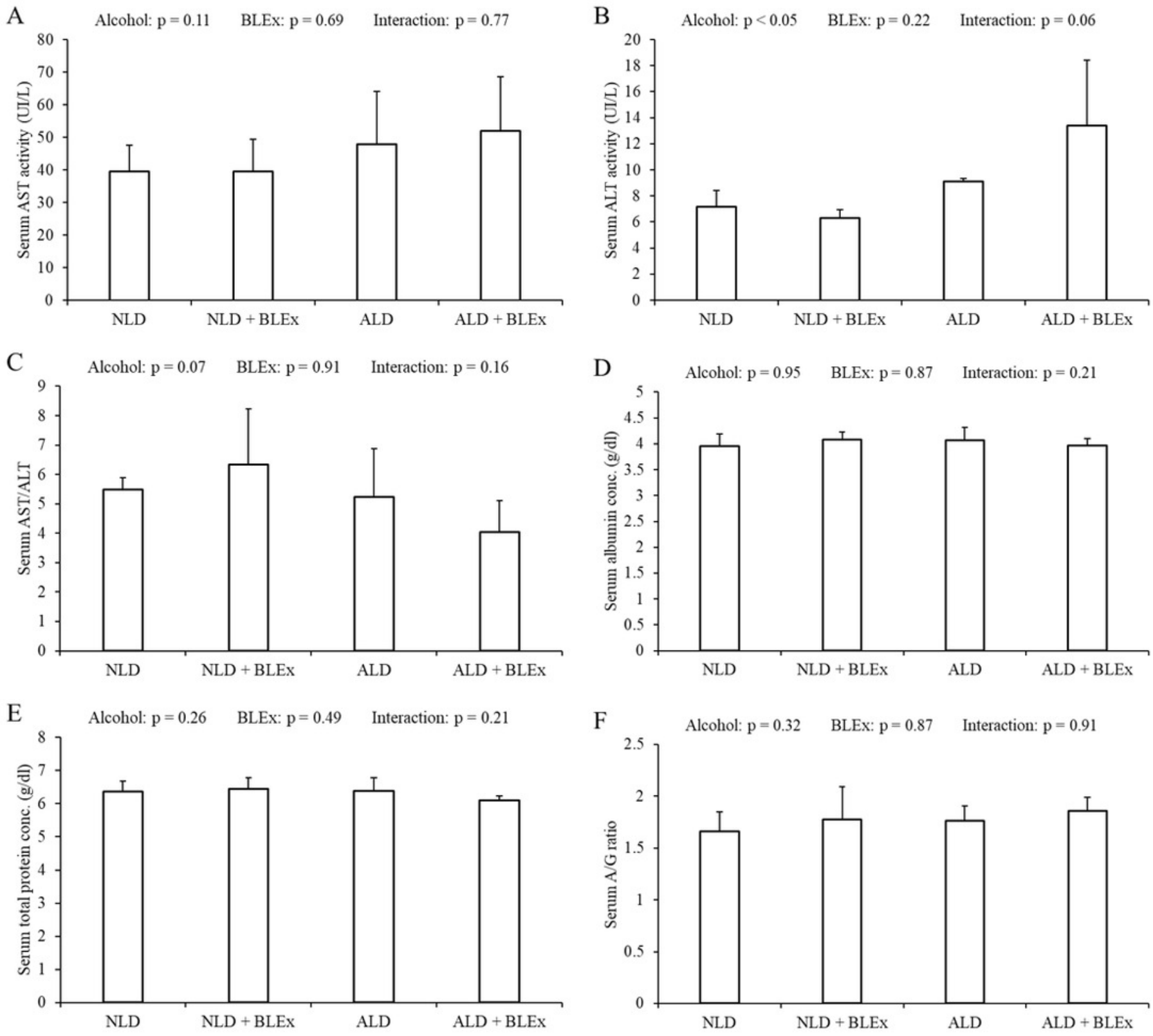
Figure 3

Level or expression of protein and mRNA related to alcohol metabolism in the liver.

(A) Liver ADH and (B) ALDH activities; liver (C) ADH1, (D) ALDH2, and (G) CYP2E1 mRNA expression; and ( $E$ and F) liver microsomal CYP2E1 protein expression in rats $(n=5)$. The values are expressed as the mean \pm SD. ${ }^{* *} p<0.01$ compared to the NLD group, and ${ }^{\# \#} p<$ 0.01 compared to the NLD + BLEx group. 

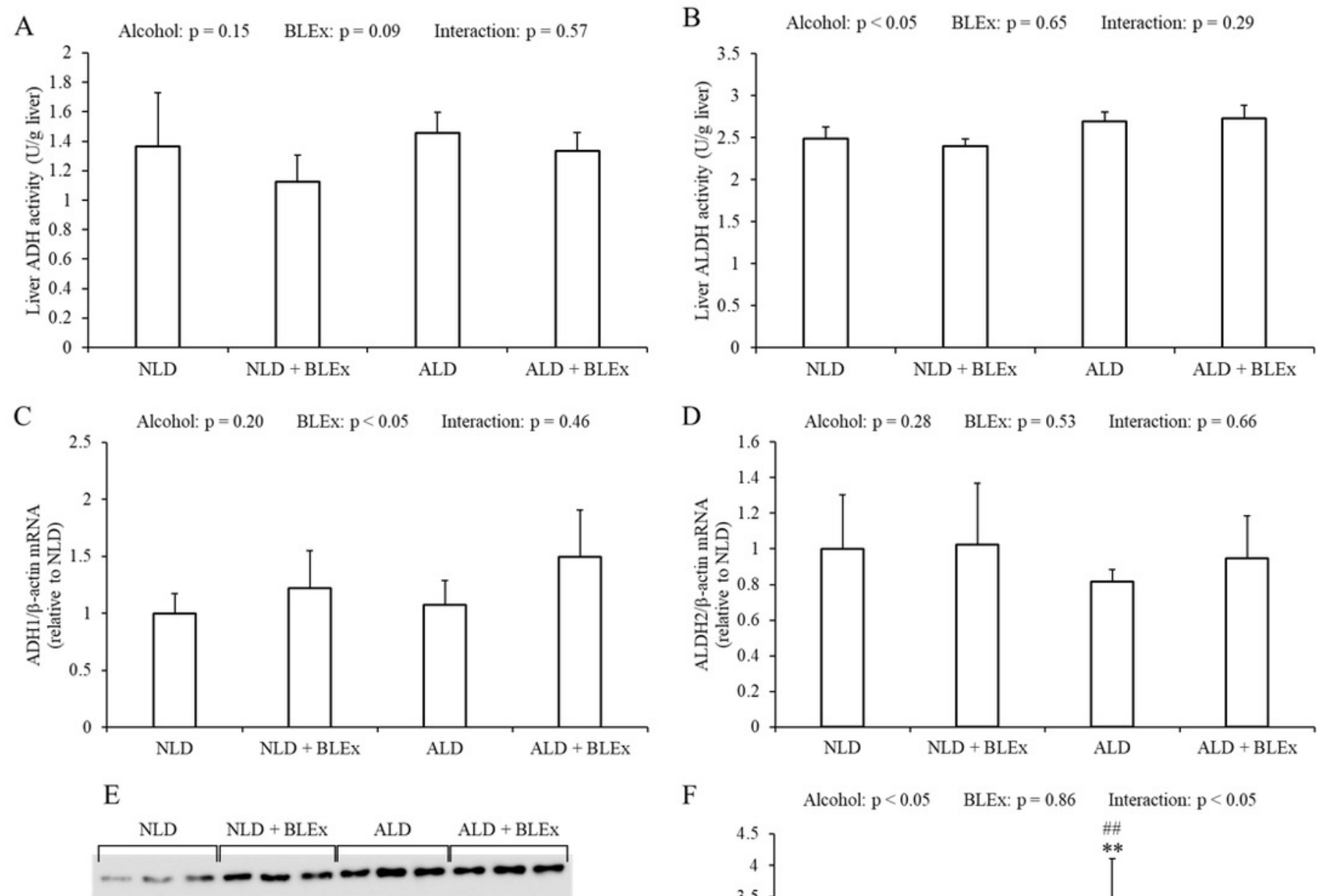

F
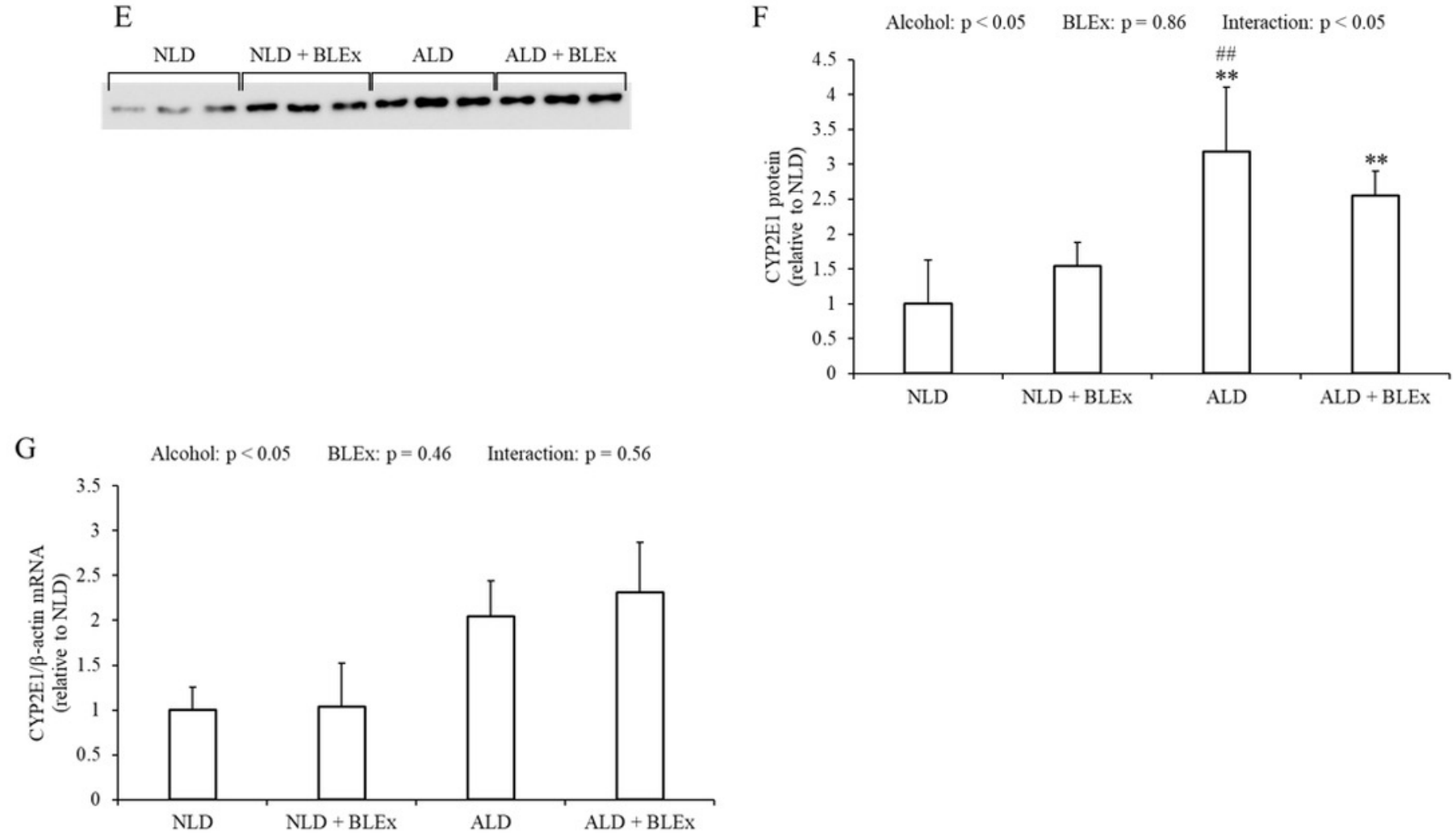
Figure 4

Liver carbonyl protein level and HO-1 mRNA expression in the liver.

(A) Liver carbonyl protein level and (B) HO-1 mRNA expression in rats $(n=5)$. The values are expressed as the mean $\pm \mathrm{SD}$. 
A

Alcohol: $p=0.10 \quad$ BLEx: $p=0.29 \quad$ Interaction: $p=0.27$

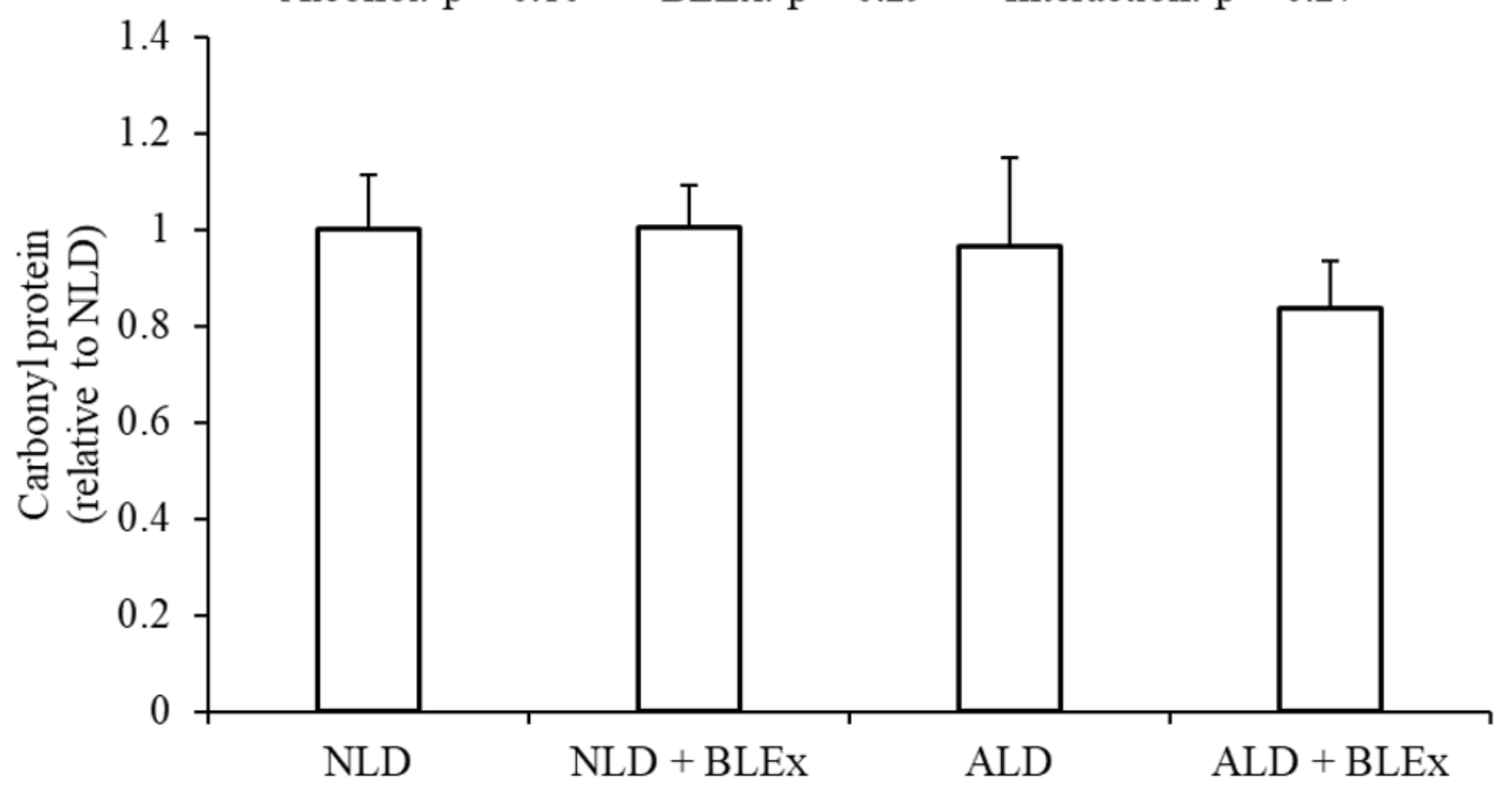

B

Alcohol: $\mathrm{p}<0.05 \quad$ BLEx: $\mathrm{p}=0.21 \quad$ Interaction: $\mathrm{p}=0.50$

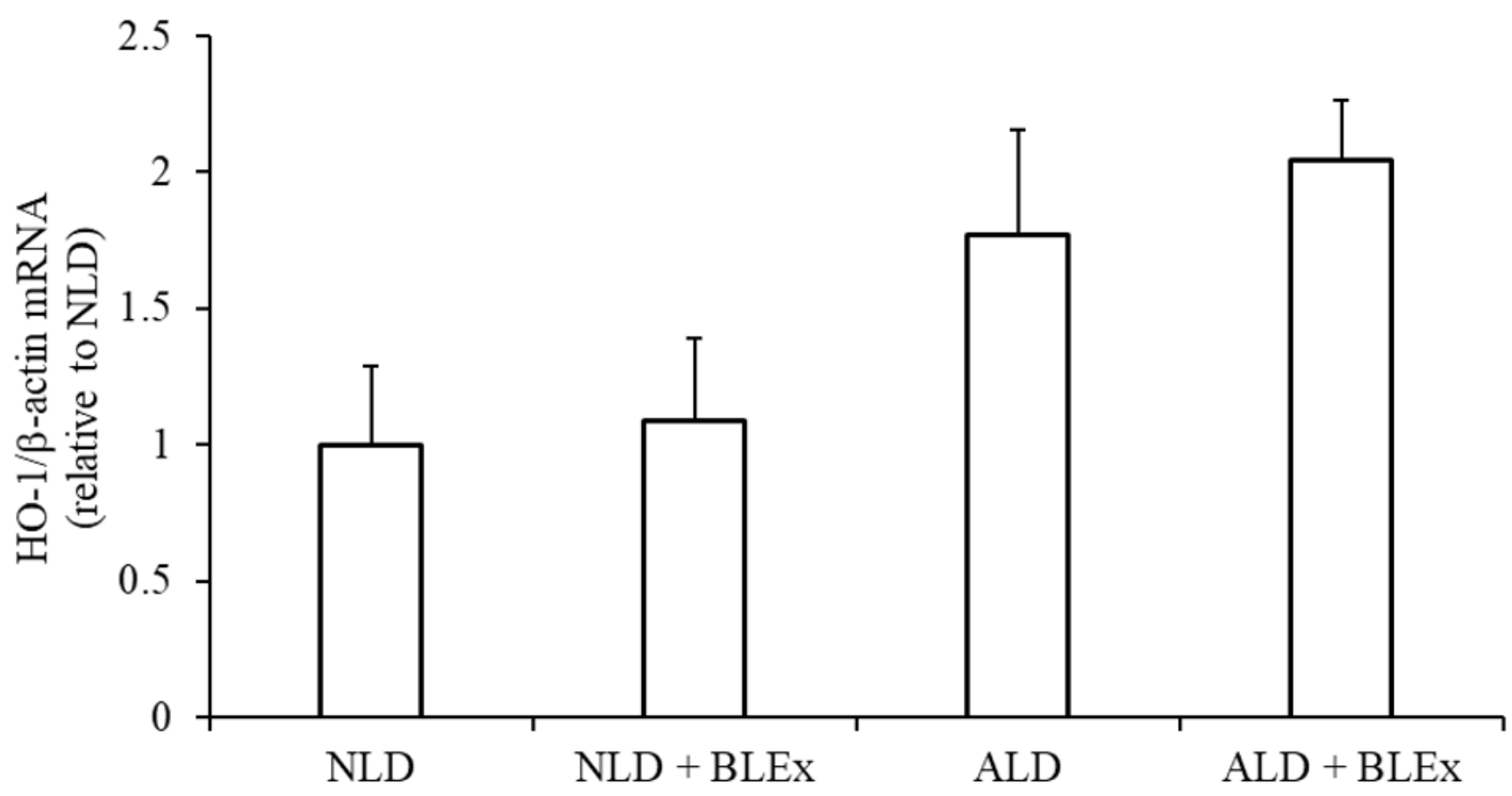


Figure 5

Liver TG and T-Chol levels in the liver.

(A) Liver triglyceride and (B) total cholesterol level in rats $(n=5)$. The values are expressed as the mean \pm SD. 
A Alcohol: $\mathrm{p}=0.66 \quad$ BLEx: $\mathrm{p}=0.89 \quad$ Interaction: 0.39

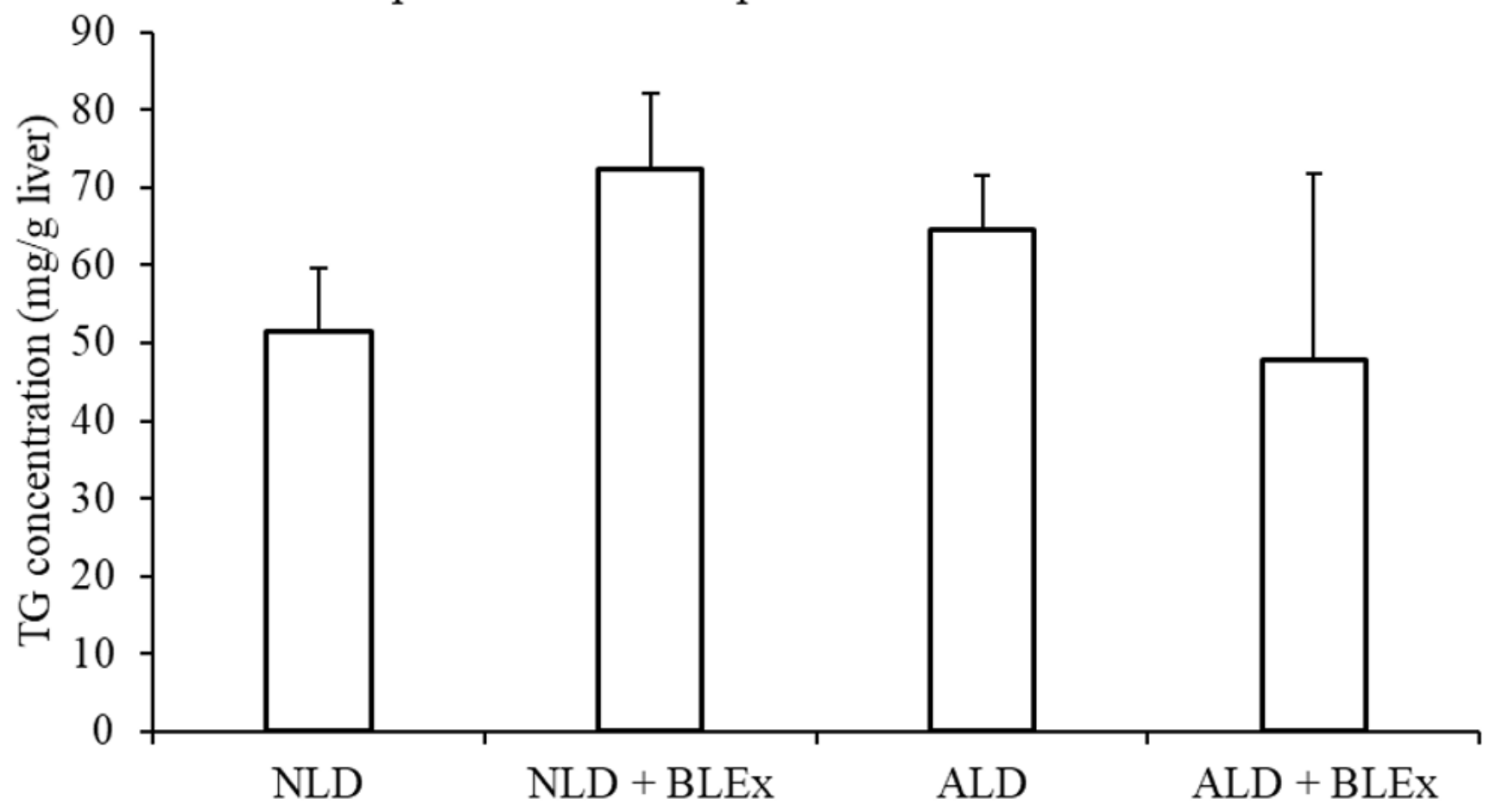

B

Alcohol: $\mathrm{p}=0.07 \quad$ BLEx: $\mathrm{p}=0.93 \quad$ Interaction: $\mathrm{p}=0.39$

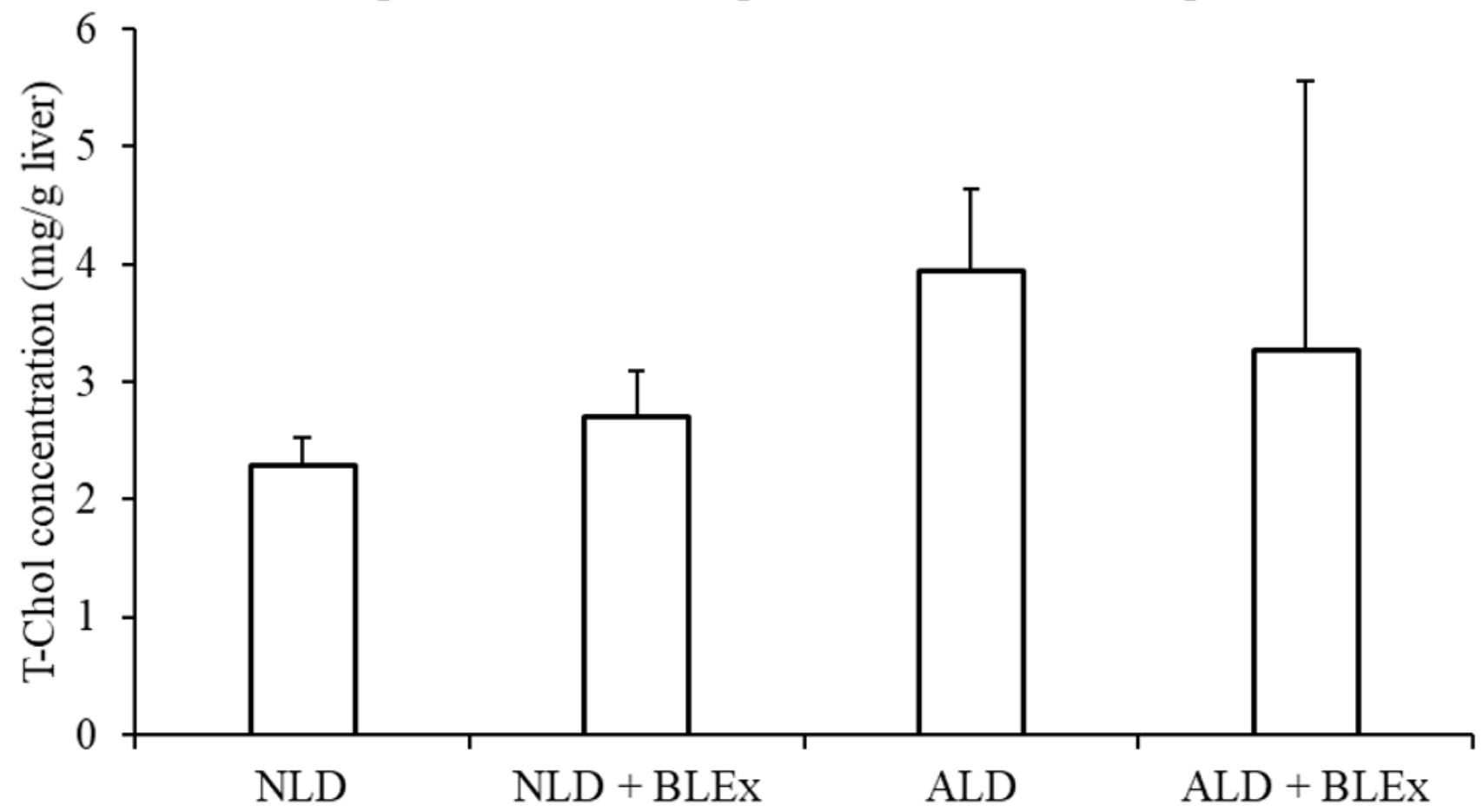




\section{Table 1 (on next page)}

Composition of the liquid diet used in this study

Composition of the liquid diet used in this study ( $\mathrm{g} / \mathrm{L}$ liquid diet). 


\begin{tabular}{lrrrr}
\hline & NLD & NLD + BLEx & ALD & ALD + BLEx \\
\hline Casein Na & 41.4 & 41.4 & 41.4 & 41.4 \\
L-cystine & 0.5 & 0.5 & 0.5 & 0.5 \\
DL-methionine & 0.3 & 0.3 & 0.3 & 0.3 \\
Corn oil & 8.5 & 8.5 & 8.5 & 8.5 \\
Olive oil & 28.4 & 28.4 & 28.4 & 28.4 \\
Safflower oil & 2.7 & 2.7 & 2.7 & 2.7 \\
Vitamin Mix & 2.5 & 2.5 & 2.5 & 2.5 \\
Mineral Mix & 8.75 & 8.75 & 8.75 & 8.75 \\
Dextrin & 115.2 & 108.5466 & 25.6 & 21.6346 \\
Cellulose & 10.0 & 10.0 & 10.0 & 10.0 \\
Choline bitartrate & 0.53 & 0.53 & 0.53 & 0.53 \\
Xanthan gum & 3.0 & 3.0 & 3.0 & 3.0 \\
BLEx & 0.0 & 6.6534 & 0.0 & 3.9654 \\
total (in dry diet) & 221.78 & 221.78 & 132.18 & 132.18 \\
Ethanol & 0.0 & 0.0 & 50.0 & 50.0 \\
\hline
\end{tabular}

1 
Table 2 (on next page)

Primer sequences used for the real-time PCR.

Primer sequences used for the real-time PCR. 


\begin{tabular}{lll}
\hline Target gene & Primer & Nucleotide sequence \\
\hline ADH1 & Forward & 5'-CCTTCACCATCGAGGACATA-3' \\
& Reverse & 5'-GCCACCATCTTAATGCGAACTT-3' \\
ALDH2 & Forward & 5'-GTGTTCGGAGACGTCAAAGA-3' \\
& Reverse & 5'-GCAGAGCTTGGGACAGGTAA-3' \\
CYP2E1 & Forward & 5'-CCTACATGGATGCTGTGGTG-3' \\
& Reverse & 5'-CTGGAAACTCATGGCTGTCA-3' \\
HO-1 & Forward & 5'-TGGCCCACGCATATACCCGCT-3' \\
& Reverse & 5'-TTGAGCAGGAAGGCGGTCTTAG-3' \\
\multirow{3}{*}{-actin } & Forward & 5'-GAGCTATGAGCTGCCTGACG-3' \\
& Reverse & 5'-GGATGTCAACGTCACACTTC-3' \\
\hline
\end{tabular}

